\title{
The Relationship between Profitability, Innovation and Technology Gap: A Basic Model
}

Ondřej Krčál ${ }^{1}$

\begin{abstract}
This paper introduces a model of innovation that explains some of the stylized facts presented in recent empirical literature. In the model, firms choose R\&D expenditures that maximize their expected profits under the assumption that R\&D expenditures of firms might be constrained by the size of their profits. Optimal decisions of firms generate relationships between profitability and innovation of individual firms that may create the observed patterns at the industry level. In particular, the model is able to explain an inverted-U relationship between profitability and innovation in the industry together with decreasing or flat and concave relationships between profitability and the dispersion of productivity in the industry. Additionally, the paper investigates the parameter space for which the model generates the observed relationships.
\end{abstract}

Key words: innovation, technology gap, profits, inverted-U relationship.

JEL Classification: L10, O30

\section{Introduction}

The relationship between competition and innovation has been widely studied by economists at least since Schumpeter's Capitalism, Socialism and Democracy, first published in 1942. In the course of the following 70 years, three important hypotheses on the shape of the relationship between competition and innovation appeared in the empirical literature. The Schumpeterian hypothesis that competition reduces innovation, the opposing hypothesis that competition encourages innovation, and a third hypothesis according to which the relationship is inverse- $U$ shaped. Even though the available data and methods used have improved substantially since Schumpeter's times, all three hypotheses find some support also in the recent empirical literature (see e.g. Kraft 1989, Artés 2009, and Hashmi 2012 for studies supporting the Schumpeterian hypothesis, Nickell 1996, Okada 2005, Gorodnichenko, Svejnar \& Terrel 2008, and Berubé, Duhamel \& Ershov 2012 for studies supporting the opposing hypothesis; and Aghion et al. 2005, Tingvall \& Poldahl 2006, and Polder \& Veldhuizen 2012 for recent studies finding the inverted-U relationship).

In the most influent recent contribution to the theoretical literature, Aghion et al. (2005) formulate a model which explains not only the decreasing or increasing relationship, but the inverted-U relationship between competition and innovation, too. However, the inverted-U relationship may emerge only if a rise in competition increases the average

\footnotetext{
${ }^{1}$ Department of Economics, Masaryk University. Address: Lipová 41a, 60200 Brno, e-mail: krcalo@mail.muni.cz
} 
difference between the technology of leader and follower firms in the economy (the difference is called technology gap in the rest of the paper). Furthermore, they find support for predictions of their model in the UK data using 1 - Lerner index as a measure of competition. Several subsequent studies find an inverted-U relationship between profitability-based measure of competition and innovation (see e.g. Hashmi 2005, Kilponen \& Santavirta 2005, Askenazy, Cahn \& Irac 2008, and Prasad 2009), but only Aghion et al. (2005) and Hashmi (2005) study the relationship between profitability and technology gap at the same time. ${ }^{2}$ While Aghion et al. (2005) discover an increasing relationship between 1 - Lerner index and technology gap, Hashmi (2005) finds a flat and concave relationship in the US data. Hence, the model by Aghion et al. (2005) is not able to explain the inverted-U relationship between profitability and innovation found by Hashmi (2005).

In order to explain the empirical evidence, I introduce a basic model of innovation in this paper. ${ }^{3}$ In the model, firms choose their R\&D expenditures in order to maximize their expected profits within certain limitations. Similarly to the model of Aghion et al. (2005) and related models such as that of Hashmi (2013), the size of innovation results from optimizing choices. ${ }^{4}$ On the other hand, the assumptions behind the basic model differ from the assumptions of Aghion et al. (2005). Most importantly, the model of Aghion et al. (2005) relates innovation to a theoretical measure of competition, which is shown to be increasing in the empirical profitability-based measure of competition (1 Lerner index). Thus their model is able to explain the empirical inverted-U relationship between profitability and innovation. The basic model explains the empirical evidence directly by relating innovation to profits of firms. This approach has two advantages: First, it avoids the problematic link between competition and profitability. As shown by Boone (2000, 2008), a rise in the level of competition may lead to both higher and lower industry profitability. Consequently, the predicted relationship between profitability and innovation might differ from the predicted relationship between competition and innovation. Second, it provides a more general explanation of the empirical evidence concerning the relationship between profitability and innovation because it covers all the possible factors responsible for variation in profitability, not only the intensity of competition like Aghion et al. (2005).

The rest of the paper is organized as follows. Section 1 introduces the model. Section 2 relates profits of firms to average $R \& D$ expenditures and the technology gap in the

\footnotetext{
${ }^{2}$ Hashmi (2005) is an earlier version of the paper Hashmi (2013). Hashmi (2013) no longer finds the inverted-U relationship between competition and innovation in the US data. However, the earlier version uses a different data set than Hashmi (2013), so by referring to Hashmi (2005) I refer to the study using the original data set.

${ }^{3}$ See Krčál (2010) for a more complex version of the model which creates similar predictions.

${ }^{4}$ Another research tradition, building on Schumpeter's views of competition and innovation, is represented by models of innovation and development in the evolutionary literature. Even though my model shares some features with the evolutionary literature (especially the more complex version presented in Krčál 2010), the main assumptions and structure of the model is different. In particular, I neither assume bounded rationality, nor do I use dynamic modeling methods (Nelson $\&$ Winter 2002).
} 
industry, and presents the conditions for which the predictions of the model are similar to the empirical findings. Section 3 discusses the robustness of the predictions to changes in parameters of the model, and the whole paper is finally concluded by Section 4 .

\section{Structure of the Model}

In this section, I introduce the model innovation. First, I introduce the determinants of firms' profits. Then I discuss the relationships between profits and the return to $R \& D$ expenditures. The section concludes with a discussion of the constraint on the size of R\&D expenditures.

The time in the model is discrete. Suppose an industry is composed of a continuum of firms. The profit of each firm is determined by industry-specific factors and firmspecific factors; ${ }^{5}$ firm-specific factors are further divided into technology and other firm-specific factors.

Industry-specific factors are those that determine profits of all firms in an industry in the same way. They include factors that affect the intensity of competition in the industry, such as the substitutability of products, entry barriers, or the possibility of tacit or explicit collusion. They may include specificities of products or their distribution, such as the level of customization of the products, or the possibility of using bundling or aftersales services for generating profits. They may also include government intervention in the industry, such as a regulatory framework or government subsidies. In the model, industry-specific factors determine the industry-specific profit $b \in\langle 0, \bar{b}\rangle$, where $\bar{b}\rangle 0$ is the maximal possible industry-specific profit.

Technology includes all feasible combinations of inputs and outputs. It can be improved by means of innovations created in the $R \& D$ process. In this model, the $R \& D$ process is structured in the following way. At the beginning of each period, firm $i$ selects the size of $\mathrm{R} \& \mathrm{D}$ expenditures $c_{i} \geq 0$. The R\&D process generates an innovation with the probability of success $p \in(0,1)$, or it fails to generate an innovation with the probability $1-p$. If $\mathrm{R} \& \mathrm{D}$ process fails to generate an innovation, the profit of firm $i$ changes by $-c_{i}$. If it generates an innovation, the profit of firm $i$ changes by the difference between the reward of innovation and R\&D expenditure $r(b) \sqrt{c_{i}}-c_{i}$, where $r(b) \geq 1$ is the reward function. Furthermore, I assume that all innovations are imitated by all other firms in the industry at the end of each period. Thus all firms have the same technology at the beginning of each period, when decisions about R\&D expenditures for the following period are made.

Other firm-specific factors are all factors other than technology that may be responsible for differences in profits of individual firms. There are two important concepts that explain the intra-industry differences in profits. First, I present the concept of strategic

\footnotetext{
${ }^{5}$ There is a large literature that studies the effect industry-specific factors and firm-specific factors on performance of firms (see e.g. Rumelt 1991, McGahan \& Porter 1997, Mauri \& Michaels 1998, Brush, Bromiley \& Hendrickx 1999, McGahan \& Porter 2002). These studies find that both industry- and firm-specific factors are important determinants of profitability of firms.
} 
groups (Caves \& Porter 1977). Strategic groups are groups of firms within an industry that share to varying degrees several structural characteristics such as width of their product line, degree of vertical integration or diversification, advertising and branding, or geographical size of the market in which they operate. Differences in these structural characteristics may lead to differences in profits of firms across groups. Firm-specific rents can be sustained in the long run because they may be protected from the competition of rival firms by so-called barriers to mobility which may arise exactly because of differences in structural characteristics of firms.

The idea of strategic groups is especially important in the context of studies that define industries using classification systems (e.g. SIC or NAICS). These industries, especially if defined relatively broadly as in Aghion et al. (2005), are not homogeneous, but rather consist of several other industries or markets. Competitive or other conditions might differ in each of the sub-industries or sub-markets.

Resource-based view of the firm is the second concept that may explain the intraindustry differences in profits. Resources are defined as "those (tangible and intangible) assets which are tied semipermanently to the firm... Examples of resources are: brand names, in-house knowledge of technology, employment of skilled personnel, trade contacts, machinery, efficient procedures, capital, etc." (Wernerfelt 1984, p. 172). According to the resource-based view, firms differ in their capacities to accumulate and use resources. This may lead to differences in their profits which can be sustained in the long run thanks to resource-position barriers. These arise if the resources are "scarce, difficult to copy or substitute, and difficult to trade in factor markets." (Hawawini, Subramanian \& Verdin 2003, p. 3)

In reality, each firm is likely to be exposed to different firm-specific factors, and therefore has a different firm-specific profit. For the sake of simplicity, I assume that there are only two types of firms in the model industry: firms $X$ and firms $Y$. The ratio of the number of firms $X$ to all firms in the industry is $q \in(0,1)$. The difference between the profits of firms $X$ and $Y$ due to other firm-specific factors is called the firm-specific profit $f \geq 0$. Specifically, other firm-specific factors increase the profits of all firms $X$ by the entire firm-specific profit $f$, while leaving the profits of firms $Y$ unchanged.

The profit of firm $i$ in any period depends not only on the size of the industry-specific profit, parameters of innovation, or on the size of the firm-specific profit, but also on whether firm $i$ has been successful in its $R \& D$ activity in the given period, and whether it is a firm of type $X$ or $Y$. The profit of firm $i$ that fails to innovate is

$$
\begin{gathered}
\pi_{i F}\left(b, c_{i}\right)=b+f-c_{i} \text { if firm } i \text { is } X, \\
\pi_{i F}\left(b, c_{i}\right)=b-c_{i} \text { if firm } i \text { is } Y,
\end{gathered}
$$

where $b \in\langle 0, \bar{b}\rangle$ represents the industry-specific profit, $f \geq 0$ is the firm-specific profit, and $c_{i} \geq 0$ is the R\&D expenditure. The profit of firm $i$ that successfully innovates is

$$
\begin{gathered}
\pi_{i S}\left(b, c_{i}\right)=b+f+r(b) \sqrt{c_{i}}-c_{i} \text { if firm } i \text { is } X, \\
\pi_{i F}\left(b, c_{i}\right)=b+r(b) \sqrt{c_{i}}-c_{i} \text { if firm } i \text { is } Y,
\end{gathered}
$$

where $r(b) \geq 1$ is the reward function. 
I assume that the reward function $r(b)$ decreases in the industry-specific profit $b$. There are several justifications for this assumption. First, suppose an industry with a constant number of firms, in which prices increase due to changes in the intensity of competition, specificities of products, specificities of the distribution process, or the form and extent of government intervention. Suppose that higher prices lead to higher profits for each firm and lower quantities of goods and services supplied by each firm. Now suppose that innovation does not substantially affect the total quantity supplied by each firm, but increases the profit margins of successful innovators by a specific amount. Then the return to $\mathrm{R} \& \mathrm{D}$ expenditures is likely to be increasing in the quantity supplied. Hence firms with higher industry-specific profits $b$, and lower quantity supplied, are likely to have lower returns to $\mathrm{R} \& \mathrm{D}$ expenditures.

Figure 1 presents a specific example in which this argument applies. Let us suppose two firms in Bertrand competition with a homogeneous product facing a decreasing demand function $D(p)$. Suppose that firms collude on a price $p_{1}<p^{M}$, where $p^{M}$ is the monopoly price. Each of them sells half of the market quantity $q_{1} / 2$ and each has a constant marginal cost $c<p_{1}$. Now suppose that an innovation reduces the marginal cost by $\Delta c$. If both firms innovate, their prices remain at the collusive level $p_{1}$ and their profits increase by $\Delta c q_{1} / 2$. If one firm innovates and the other does not, the innovator can either sustain collusion, or compete with the other firm and sell competitive quantity $q^{C}$ at the competitive price $p^{C}=c$. Suppose the collusive price $p_{1}$ is high enough so that $\left(p_{1}-c+\right.$ $\Delta c) q_{1} / 2>\Delta c q^{C}$, which means that it is more profitable for the innovator to sustain the collusive price. Then the profit of the innovator increases by $\Delta c q_{1} / 2$, too. Suppose now that the firms are able to collude on a price $p_{2}>p_{1}$ such that $p_{2} \leq p^{M}$, and each of them sells quantity $q_{2} / 2<q_{1} / 2$ and earns profit $\left(p_{2}-c\right) q_{2} / 2>\left(p_{1}-c\right) q_{1} / 2$. Assuming that $\left(p_{2}-\right.$ $c+\Delta c) q_{2} / 2>\Delta c q^{C}$, the incremental profit from innovation (reward) is $\Delta c q_{2} / 2<\Delta c q_{1} / 2$. Hence firms with higher profits have lower returns to R\&D expenditures.

Second justification of the decreasing reward function is as follows: Suppose an industry serves several markets, each with a decreasing demand function (for example the pharmaceutical industry serves several markets for different types of drugs). Now suppose that innovation provides the successful innovator with a monopoly in one of the markets. Then the return to $R \& D$ expenditures is equal to the difference between the monopoly profit and the profit the innovator had earned before the innovation was implemented. If the industry-specific profit $b$ is low, the incremental profit due to the monopolistic position in the market is high. On the other hand, if the firm earns high industry-specific profit $b$ under competition, the reward is low. Hence the return to $\mathrm{R} \& \mathrm{D}$ expenditures is likely to be decreasing in industry-specific profit $b$ in this situation.

And third, suppose an industry with firms at the same technological level. The interaction in the market becomes less aggressive (Boone 2008). A reduction in the aggressiveness of interaction can be modeled for example as a reduction in the elasticity of substitution between the goods, a rise in transport cost in the Hotelling model, or as a switch from Bertrand to Cournot. Then firms earn higher profits but their rewards tend to be lower. This effect arises mainly because less aggressive interaction leads to a lower reallocation of market shares from less to more efficient firms. Hence a higher firmspecific profit $b$ due to a less aggressive interaction may be related to a lower return to R\&D expenditures. 
Figure 1 An Explanation of Decreasing Return to R\&D Expenditures

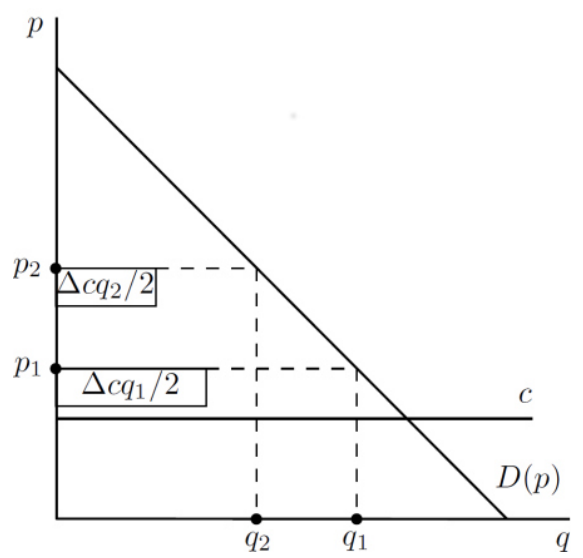

The figure shows the effect of an increase in price on the reward in Bertrand competition with two firms. If the collusive price increases from $p_{1}$ to $p_{2}$, the quantity sold by each firm decreases from $q_{1} / 2$ to $q_{2} / 2$. Assuming that the innovation reduces the marginal cost by $\Delta c$, the reward is likely to fall from $\Delta c q_{1} / 2$ to $\Delta c q_{2} / 2$.

In this model, the reward function is given by

$$
r(b)=\frac{1}{p}\left(1+R-\sigma\left(\frac{b}{b_{\max }}\right)\right),
$$

where the slope parameter $\sigma>0$ determines the effect of the industry-specific profit $b$ on the reward from innovation, and the opportunity parameter $R \geq \sigma>0$ determines the attractiveness of innovation (the assumption $R \geq \sigma$ is equivalent to the assumption that $r \geq 1$ ). The specific form of the reward function in (3) has two advantages: First, the reward function $r(b)$ varies with the probability of success $p$ so that changes in $p$ do not affect the return to $R \& D$ expenditures. This way, it is possible to isolate the effect of different probabilities of success from the changes in the attractiveness of innovation measured by the opportunity parameter $R$. Second, the opportunity parameter $R$ has an intuitive interpretation. It is equal to the return to the first unit of R\&D expenditures $\left(c_{i}\right.$ $=1)$ in an industry with the lowest industry-specific profit $(b=0)$.

And finally, I assume that firm $i$ chooses $\mathrm{R} \& \mathrm{D}$ expenditures $c_{i}$ so that it is not in loss even if the innovation fails. It follows from (1) that

$$
\begin{gathered}
c_{i} \leq b+f \text { for firms } X, \\
c_{i} \leq b \text { for firms } Y,
\end{gathered}
$$

There are several ways to justify this assumption: First, firms might face credit constraints. If firms are not able to obtain credit, they must finance their R\&D activities from their current profits even if they fail to innovate. This assumption may also be justified if firms are able to obtain credit because, in that case, the banks might be reluctant to provide them with credit that could not be fully repaid in the event that the R\&D 
activity failed. Moreover, in a slightly modified model, the main results would hold even if the maximum $R \& D$ expenditure was equal to the expected profit of the firm. This size of $R \& D$ expenditures is clearly the maximum sustainable size of the $R \& D$ budget of the firm.

Second, firms might be infinitely risk averse, which means that they choose their R\&D expenditures so that their profits in the worst possible outcome are non-negative (this version of infinite risk aversion is used for example by Rey \& Tirole 1986). The predictions of the model are likely to be similar even if the risk aversion of firms was not infinite but if it was very high for low profits and decreasing in the profits of firms, because the shape of the utility function would resemble the prospect-theory value function (see Krčál 2010).

Third, managers of firms might be infinitely risk averse. If their compensation is linked to the performance of their firms (e.g. they earn a percentage of their profits), managers of low-profit firms would avoid high $\mathrm{R} \& \mathrm{D}$ expenditures. The model might also provide similar predictions if the risk aversion of managers was high for low compensation and decreasing in the size of managerial compensation, or if managers had prospect-theory preferences (see Krčál 2010).

The basic setup of the model can be summarized as follows. Each firm chooses R\&D expenditures that maximize its expected profit subject to the R\&D-expenditure constraints (4). Firm $i$ chooses $c_{i}$ in order to maximize

$$
\begin{gathered}
p\left(b+f+r(b) \sqrt{c_{i}}-c_{i}\right)+(1-p)\left(b+f-c_{i}\right) \text { s.t. } c_{i} \leq b+f \text { if firm } i \text { is } X, \\
p\left(b+f+r(b) \sqrt{c_{i}}-c_{i}\right)+(1-p)\left(b-c_{i}\right) \text { s.t. } c_{i} \leq b \text { if firm } i \text { is } Y,
\end{gathered}
$$

where $p \in(0,1)$ represents the probability of success, $\mathrm{b} \in\langle 0, \overline{\mathrm{b}}\rangle$ is the industry-specific profit, $f \geq 0$ is the firm-specific profit, $r(b) \geq 1$ is the reward function, and $c_{\mathrm{i}} \geq 0$ is the $\mathrm{R} \& \mathrm{D}$ expenditure.

\section{Predictions of the Model}

In this section, I show that the model can explain the empirical findings of Aghion et al. (2005) and Hashmi (2005) for some combinations of parameters. First, I find the optimal R\&D expenditures of firms $X$ and $Y$. Then I discuss the relationship between the industry-specific profit and average R\&D expenditures in the industry. Finally, I derive the relationship between industry-specific profit and the technology gap.

Using Kuhn-Tucker conditions for solving the constrained maximization problems (5) and (6), I obtain the optimal R\&D expenditures of firms $X$ and $Y$

$$
c_{i}^{X}=\min \left\{b+f, c_{i}^{*}(b)\right\},
$$

and

$$
c_{i}^{Y}=\min \left\{b, c_{i}^{*}(b)\right\}
$$

where 


$$
c_{i}^{*}(b)=\frac{1}{4}\left(1+R-\frac{\sigma b}{\bar{b}}\right)^{2} .
$$

In the following paragraphs, I discuss the conditions under which the functions $c_{i}^{Y}(b)$ and $c_{i}^{X}(b)$ are inverse $\mathrm{V}$-shaped. The function $c_{i}^{Y}(b)$ is inverse $\mathrm{V}$-shaped if it peaks at $b>0$, that is if $c_{i}^{*}(0)>0$, and at the same time if it peaks at $b<\bar{b}$, that is if $c_{i}^{*}(\bar{b})<\bar{b}$. Hence the function $c_{i}^{Y}(b)$ is inverse $\mathrm{V}$-shaped if $c_{i}^{*}(\bar{b})-\bar{b}<0<c_{i}^{*}(0)$, that is if

$$
\frac{1}{4}\left(1+R-\frac{\sigma \bar{b}}{\bar{b}}\right)^{2}-\bar{b}<0<\frac{1}{4}(1+R)^{2} .
$$

Since $R \geq \sigma>0$, the right-hand side of the inequality is always higher than zero. Hence $c_{i}^{Y}(b)$ is inverse $\mathrm{V}$-shaped if

$$
(1+R-\sigma)^{2}-4 \bar{b}<0 .
$$

The function $c_{i}^{X}(b)$ is inverse $\mathrm{V}$-shaped if $c_{i}^{*}(b)-f-\bar{b}<c_{i}^{*}(0)-f$, that is if

$$
(1+R-\sigma)^{2}-4(f+\bar{b})<0<(1+R)^{2}-4 f .
$$

It follows from condition (10) that the function $c_{i}^{Y}(b)$ is inverse-V shaped if the opportunity parameter $R$ is relatively low, that is if $R<2 \sqrt{\bar{b}}+\sigma-1$. Furthermore, if condition (10) holds, the left-hand side of condition (11) also holds because the firm-specific profit $f \geq 0$. It means that if the function $c_{i}^{Y}(b)$ is inverse $\mathrm{V}$-shaped, the function $c_{i}^{X}(b)$ is either inverse $\mathrm{V}$-shaped or decreasing in the industry-specific profit $b$.

Next, I discuss the shape of the relationship between the industry-specific profit and average $R \& D$ expenditures in the industry, called the $R \& D$ function. The R\&D function is given by

$$
c(b)=q c_{i}^{X}(b)+(1-q) c_{i}^{Y}(b),
$$

where $q$ is the proportion of firms $X$ in the industry. Let $b^{*}$ denote the industry-specific profit that corresponds to the maximum of the R\&D function $c(b)$. If $0<b^{*}<\bar{b}$, the maximum of the R\&D function lies within the range of industry-specific profit $b \in$ $\langle 0, \bar{b}\rangle$. Hence the R\&D function $c(b)$ is likely to be inverse U- or V-shaped. I assume that condition (10) holds which means the function $c_{i}^{Y}(b)$ is inverse $\mathrm{V}$-shaped, and the function $c_{i}^{X}(b)$ is either inverse $\mathrm{V}$-shaped or decreasing in the industry-specific profit $b$. If the firms-specific profit is relatively low, so that

$$
f<\frac{1}{4}(1+R)^{2}
$$

the R\&D-expenditure function of firms $X c_{i}^{X}(b)$ is inverse $\mathrm{V}$-shaped (see (11)). Then the maximum of the R\&D function $c(b)$ is at $0<b^{*}<\bar{b}$. The shape of the function depends on the firm-specific profit $f$ :

- If $f=0$, the R\&D function $c(b)$ has the same inverted-V shape as the R\&Dexpenditure functions of firms $X$ and firms $Y$. See Panel 2A for an example of an inverse $\mathrm{V}$-shaped $c(b)$.

- If $0<f<\frac{1}{4}(1+R)^{2}$, the shapes of $c_{i}^{X}(b)$ and $c_{i}^{Y}(b)$ are different. Because the R\&D function $c(b)$ is a weighted average of $c_{i}^{X}(b)$ and $c_{i}^{Y}(b)$, the maxi- 
mum of the R\&D function $c(b)$ is at $0<b^{*}<\bar{b}$. See Panel 2B for an example of the corresponding (inverted-U) R\&D function $c(b)$.

Figure 2: Examples of R\&D-Expenditure Functions

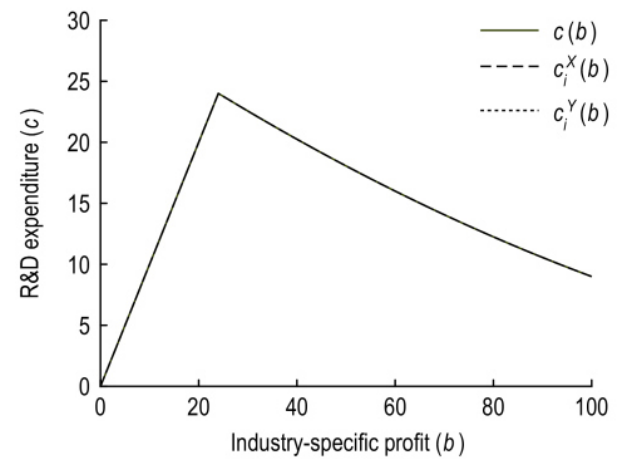

A: $f=0, q=0.5$

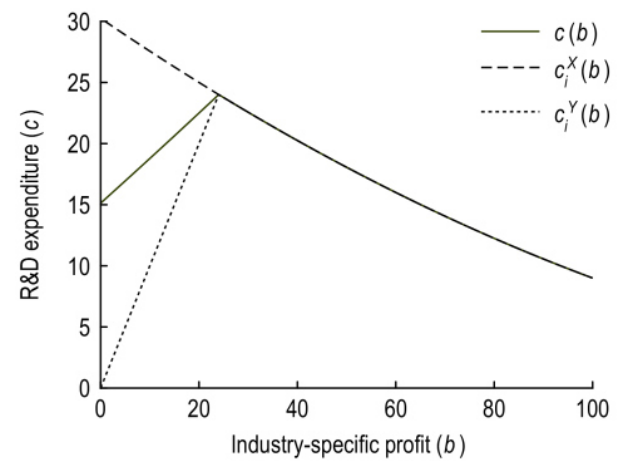

C: $f=35, q=0.5$

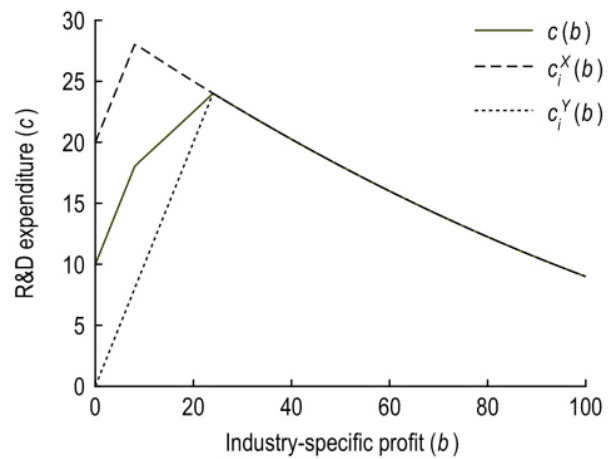

B: $f=20, q=0.5$

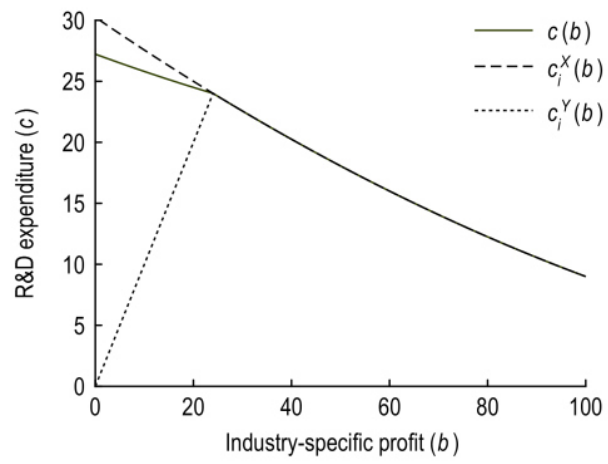

$\mathrm{D}: f=35, q=0.9$

The figure shows examples of $R \& D$ expenditure functions of firms $X c_{i}^{X}(b)$, firms $Y c_{i}^{Y}(b)$, and of an average firm $c(b)$. The parameters common to all panels are $R=10, \sigma=5, p=0.5$, and $\bar{b}=100$.

If the firms-specific profit is relatively high, so that

$$
f \geq \frac{1}{4}(1+R)^{2}
$$

the R\&D-expenditure function of firms $X c_{i}^{X}(b)$ is decreasing in $b$. Then the shape of the R\&D function $c(b)$ depends on the slope of $c_{i}^{Y}(b)$ :

- In the higher part of the industry-specific-profit range where $c_{i}^{Y}(b)=c_{i}^{*}(b)$, the part of the R\&D function $\bar{c}(b)$ is clearly decreasing.

- In the lower part of the industry-specific-profit range where $c_{i}^{Y}(b)=b$, the slope of the part of the R\&D function $\underline{c}(b)$ is given by 


$$
\frac{\delta \underline{c}(b)}{\delta b}=-\frac{q p \sigma}{2 \bar{b}}\left(1+R-\sigma \frac{b}{\bar{b}}\right)+(1-q) .
$$

The function $\underline{c}(b)$ is convex because

$$
\frac{\delta^{2} \underline{c}(b)}{\delta b^{2}}=\frac{q \sigma^{2}}{2 \bar{b}^{2}}>0 .
$$

Thus the function $\underline{c}(b)$ is increasing in $b$, if the slope of $\underline{c}(b)$ is positive for $b=0$. Substituting $b=0$ into (13) and solving for $R$, I find that $\underline{c}(b)$ is increasing if

$$
R<\frac{2 \bar{b}}{q \sigma}(1-q)-1 .
$$

Because the part of the R\&D function $\bar{c}(b)$ is always decreasing, the entire R\&D function $c(b)$ is inverse $\mathrm{V}$-shaped if $\underline{c}(b)$ is increasing, that is if

$$
R \geq \frac{2 \bar{b}}{q \sigma}(1-q)-1 .
$$

For an example of this outcome, see Panel 2C. For an example of the outcome where condition (14) does not hold, see Panel 2D.

Next, I discuss the shape of the relationship between the industry-specific profit and the technology gap. The measure of the technology gap used in Aghion et al. (2005) and Hashmi (2005) is the industry average of firm-level technology gaps, where the technology gap of firm $i$ is given by

$$
\frac{T F P_{L}-T F P_{i}}{T F P_{L}},
$$

where $T F P_{L}$ is total factor productivity of the technology leader, and $T F P_{i}$ is total factor productivity of firm $i$. TFP is usually calculated as value added divided by a weighted average of input units used in production.

In the context of my model, firm $i$ may have relatively high total factor productivity compared to other firms for two reasons:

- $\quad$ Firm $i$ has better technology which means that it has higher revenue or lower costs than other firms. The reward $r(b) \sqrt{c_{i}}$ is the measure of the size of technology.

- If firm $i$ has a higher profit due to other firm-specific factors, it might mean that its structural characteristics or resources make it possible for the company to have higher revenue using similar quantities of inputs. If firm $i$ has a positive firm-specific profit $f$, it is likely to have higher TFP than firms with no firm-specific profit.

Consequently, I define the technology gap as an average difference between profits of leaders and other firms in the industry due to technology or other firm-specific factors. The technology gap is determined by the distribution of technology after the innovation. 
There are four groups of firms with different technology gaps after the innovation in a given period:

- $\quad$ Successful innovators $X$ with the technology gap $G_{S}^{X}=0$.

- $\quad$ Failed innovators $X$ with the technology gap $G_{F}^{X}(b)=r(b) \sqrt{c_{i}^{X}(b)}$.

- Successful innovators $Y$ with the technology gap $G_{S}^{Y}(b)=f+r(b) \sqrt{c_{i}^{X}(b)}-$ $r(b) \sqrt{c_{i}^{Y}(b)}$

- $\quad$ Failed innovators $Y$ with the technology gap $G_{F}^{Y}(b)=f+r(b) \sqrt{c_{i}^{X}(b)}$.

Weighting the differences in profits by the share of different groups of firms in the industry, we get the technology-gap function

$$
G(b)=q p G_{S}^{X}+q(1-p) G_{F}^{X}(b)+(1-q) p G_{S}^{Y}(b)+(1-q)(1-p) G_{S}^{Y}(b) .
$$

Let $b^{G *}$ denote the industry-specific profit that corresponds to the maximum of the technology-gap function $G(b)$. If $0<b^{G *}<\bar{b}$, the maximum of the technology-gap function lies within the range of industry-specific profit $b \in\langle 0, \bar{b}\rangle$. Hence the technology-gap function $G(b)$ is likely to be either inverse V- or U-shaped. On the other hand if $b^{G *}=0$, the maximum lies at the lowest possible industry-specific profit $b=0$, and the technology-gap function is likely to be decreasing in $b$.

In this subsection, I discuss the shape of the technology-gap function if the condition (10) holds, which implies that $c_{i}^{Y}(b)$ is inverse V-shaped and $c_{i}^{X}(b)$ is decreasing or inverse $\mathrm{V}$-shaped. If the firm-specific profit is relatively high so that

$$
f \geq \frac{1}{4}(1+R)^{2}
$$

the function $c_{i}^{X}(b)$ is decreasing in the industry-specific profit $b$. Then the technologygap function $G(b)$ is decreasing in $b$ because the technology-gaps of failed innovators $X$ and $Y G_{F}^{X}(b)$ and $G_{F}^{Y}(b)$ and of successful innovators $Y G_{S}^{Y}(b)$ are decreasing in the industry-specific profit $b$. The technology-gaps $G_{F}^{X}(b)=r(b) \sqrt{c_{i}^{X}(b)}$ and $G_{F}^{Y}(b)=$ $f+r(b) \sqrt{c_{i}^{X}(b)}$ are decreasing because both $r(b)$ and $c_{i}^{X}(b)$ are decreasing in the industry-specific profit $b . G_{S}^{Y}(b)=f+r(b)\left(\sqrt{c_{i}^{X}(b)}-\sqrt{c_{i}^{Y}(b)}\right)$ is decreasing in $b$ because $r(b)$ is decreasing in $b$ and

$$
\begin{gathered}
\sqrt{c_{i}^{X}(b)}-\sqrt{c_{i}^{Y}(b)}=\sqrt{c_{i}^{*}(b)}-\sqrt{b} \text { if } b \leq c_{i}^{*}(b) \\
\sqrt{c_{i}^{X}(b)}-\sqrt{c_{i}^{Y}(b)}=0 \text { if } b \geq c_{i}^{*}(b)
\end{gathered}
$$

is either decreasing in $b$ or zero.

If the firm-specific profit is relatively low so that

$$
f<\frac{1}{4}(1+R)^{2}
$$

the function $c_{i}^{X}(b)$ is inverse $\mathrm{V}$-shaped. Then the shape of the technology-gap function depends on the slope of $c_{i}^{X}(b)$ : 
- In the higher part of the range of industry-specific profit where $c_{i}^{X}(b)=c_{i}^{*}(b)$ (the function $c_{i}^{*}(b)$ is decreasing in $b$ ), the technology-gap function $\bar{G}(b)$ is always decreasing in $b$ for the reasons explained in the previous paragraph.

- In the lower part of the industry-specific-profit range where $c_{i}^{X}(b)=b+f$, the shape of the part of the technology-gap function $\underline{G}(b)$ depends on the size of the firm-specific profit $f$ :

If $f=0$, the function $\underline{G}(b)$ is increasing at low industry-specific profit $b$ because the technology gap is zero for $b=0$ and positive for $b>0$.

If $0<f<\frac{1}{4}(1+R)^{2}$, the function $\underline{G}(b)$ may be both increasing or decreasing because $\frac{\partial \underline{G}(b)}{\partial b}$ may be positive or negative. What we know is that the slope of $\underline{G}(b)$ is decreasing in the firm-specific profit $f$ because

$$
\frac{\partial^{2} \underline{G}(b)}{\partial b \partial f}=\left(\frac{1}{p}-q\right)\left(-\frac{1+R-\frac{\sigma b}{\bar{b}}}{4(b+f)^{\frac{3}{2}}}-\frac{\sigma}{2 \bar{b} \sqrt{b+f}}\right)<0 .
$$

To summarize, if condition (10) holds $\left(c_{i}^{Y}(b)\right.$ is inverse V-shaped), the shape of the entire technology-gap function $G(b)$ depends primarily on the firm-specific profit $f$ :

- If $f=0$, then $0<b^{*}<\bar{b}$ and the technology-gap function is inverse V-because $\bar{G}(b)$ is decreasing in the industry-specific profit $b$ and $\underline{G}(b)$ is increasing at low $b$.

- If $0<f<\frac{1}{4}(1+R)^{2}$, then $b^{G *}<\bar{b}$, which means that the technology-gap function is likely to be either decreasing or inverse $\mathrm{U}$ - or V-shaped. Moreover, the slope of the part of the technology-gap function $\underline{G}(b)$ in this situation decreases with increasing firm-specific profit $f$. It means that the entire technology-gap function $G(b)$ is more likely to have the maximum at $b=0$ if the firmspecific profit $f$ is high.

- If $f>\frac{1}{4}(1+R)^{2}$, the technology-gap function $G(b)$ is always decreasing in $b$.

Figure 3 shows examples of the R\&D functions $c(b)$ and the technology-gap functions $G(b)$ for different levels of the firm-specific profit $f$. If $f$ is low, the R\&D function $c(b)$ and the technology-gap function $G(b)$ are first increasing and then decreasing in industry-specific profit. The shapes of these functions roughly correspond to relationships found by Hashmi (2005). The higher the $f$, the more decreasing is the part of the technology-gap function $\underline{G}(b)$ corresponding to the low industry-specific profits $b$. The shapes of both functions resemble to the shapes of the relationships found by Aghion et al. (2005).

\section{Robustness of the Model}

In this section, I discuss the robustness of predictions of the basic model for the maximum industry-specific profit $\bar{b}=100$. First, I discuss the properties of the parameter space for which the R\&D function $c(b)$ has maximum at the industry-specific profit $0<$ $b^{*}<100$, forming an inverted-V or inverted-U relationship. Then I present the condi- 
tions for which the technology-gap function $G(b)$ has maximum at $b^{G_{*}}=0$ or $0<b^{G_{*}}<$ 100 .

Figure 3: Examples of R\&D and Technology-Gap Functions

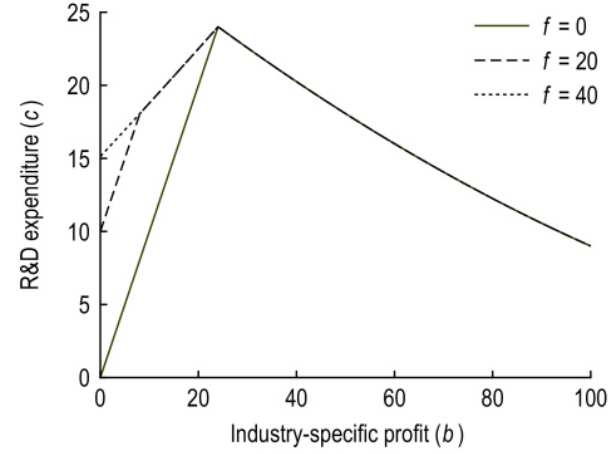

A

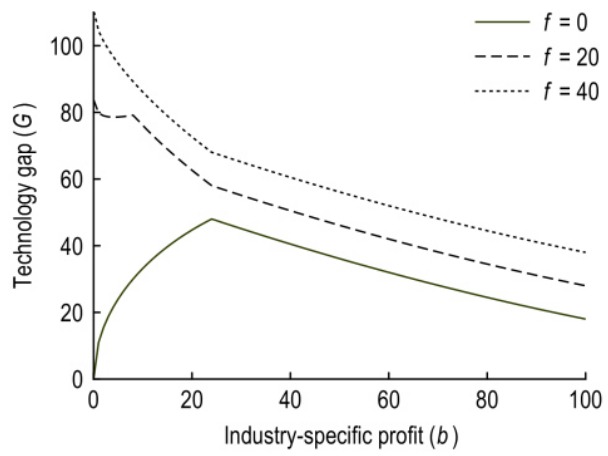

B

The figure shows examples of the R\&D expenditure of an average firm $c(b)$ and of the technology-gap function $G(b)$ for different levels of the firm-specific profit $f$. The parameters common to all panels are $R=10, \sigma=5, p=0.5, q=0.5$, and $\bar{b}=100$.

For clarity of presentation, I split the parameter space into two parts depending on the relative size of the firm-specific profit $f$. I have shown in the previous section that if the firm-specific profit is low enough so that

$$
f<\frac{1}{4}(1+R)^{2}
$$

the $\mathrm{R} \& \mathrm{D}$ function $c(b)$ is inverse $\mathrm{U}$ - or $\mathrm{V}$-shaped if the opportunity parameter

$$
R \geq \sigma(L B) \text { and } R<19-\sigma\left(U B_{1}\right),
$$

where $\sigma>0$ is the slope parameter. Panel 4A presents the parameter space described by condition (18). The R\&D function is inverse $\mathrm{V}$ - or $\mathrm{U}$-shaped for all combinations of the opportunity parameters $R$ and the slope parameters $\sigma$ corresponding to the points between the upper and lower boundaries. The panel shows that the distance remains constant for different values of the slope parameter $\sigma$. On the other hand, if the firm-specific profit is high enough so that

$$
f \geq \frac{1}{4}(1+R)^{2}
$$

the $R \& D$ function is inverse $\mathrm{V}$-shaped if the opportunity parameter

$$
R \geq \sigma(L B) \text { and } R<19-\sigma\left(U B_{1}\right) \text { and } R<\frac{200}{q \sigma}(1-q)-1\left(U B_{2}\right),
$$

where $q \in\langle 0,1\rangle$ is the share of firms $X$ in the industry. There is one lower boundary $L B$ and two upper boundaries $U B_{1}$ and $U B_{2}$. If $U B_{1} \leq U B_{2}$, we have the same situation as in (18). If $U B_{1}>U B_{2}$, the difference between the boundaries is decreasing in the share of firms $X$ in the industry $q$ and slope parameter $\sigma$ and constant in all other parameters. Panels 4B present three parts of the parameter space determined by conditions (19) for 
the slope parameters $\sigma=5,10$, and 15. The R\&D function $c(b)$ is inverse $\mathrm{V}$-shaped for all combination of the opportunity parameter $R$ and the share of firms $X$ in the industry $q$ that correspond to points within the areas to the left of the lines (the lower horizontal line is $L B$, the upper horizontal line $U B_{1}$, the decreasing line $U B_{2}$ ). The panels show that a reduction in the slope parameter $\sigma$ increases the parameter space for which the $R \& D$ function $c(b)$ is inverse $\mathrm{V}$-shaped.

Figure 4: Combinations of Parameters for which $0<b *<100$

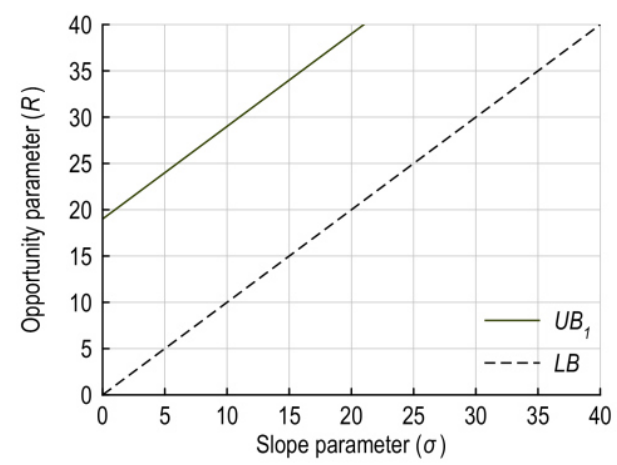

$\mathrm{A}: f<0.25(1+R)^{2}$

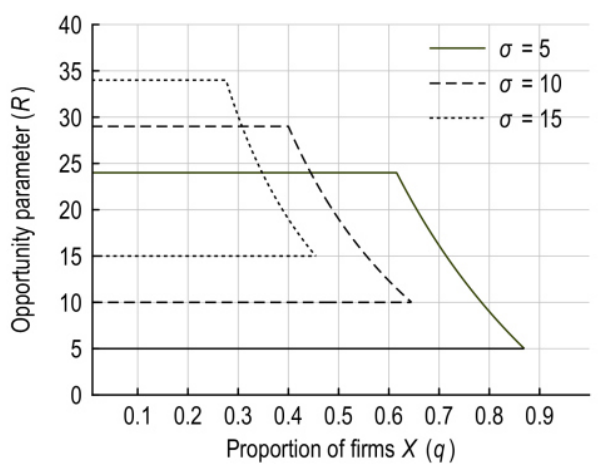

B: $f \geq 0.25(1+R)^{2}$

The figure shows the combinations of parameters for which $0<b^{*}<100$. The parameter combinations lie between the lines $L B$ and $U B_{1}$ in Panel $A$, and in the area to the left of the lines in Panel B.

Figure 5 presents the parameter space that determines the shape of the technology-gap function $G(b)$ given condition (10) holds. The lines are given by $f=\frac{1}{4}(1+R)^{2}$, or inversely by $R=2 \sqrt{f}-1$. The technology-gap function $G(b)$ is inverse V-shaped for all parameters along the vertical axis $(f=0)$. It is decreasing for all combinations of parameters corresponding to the points to the right of the line. For the remaining combinations of parameters, the technology-gap function $G(b)$ has the maximum either at $0<$ $b^{G_{*}}<100$ or at $b^{G_{*}}=0$.

The main findings of this section are as follows: If the firm-specific of profit $f$ is low, the predictions consistent with the findings of Hashmi (2005) are generated for a wider range of other parameters. On the other hand, if $f$ is high, the predictions correspond to the empirical findings of Aghion et al. (2005) for a wider range of parameters. We may use a higher firm-specific profit $f$ for explaining the empirical findings of Aghion et al. (2005) and a lower $f$ for explaining the findings of Hashmi (2005), because Aghion et al. (2005) use broader definition of industries (two-digit SIC code) than Hashmi (2005) (four-digit SIC code). The intuition behind this reasoning is straightforward. Firms in more broadly-defined industries are likely to differ more in their structural characteristics or resources. Therefore, the differences in profits due to other firm-specific factors are likely to be higher in such industries. This assumption is also supported by the difference in the technology gap found in Aghion et al.'s UK data and Hashmi's US data. 
Despite the fact that the patent citation per industry is substantially lower in the UK data than in the US data (the mean citation-weighted patents are 6.6 in the UK and 16.6 in the US data), on average, the technology gap is higher in the UK data (the mean technology gap is 0.35 in the UK and 0.22 in the US data) (Hashmi 2005, p. 12). The firmspecific profit $f$ is therefore likely to be higher in the UK than in the US data.

\section{Figure 5 Combinations of Parameters That Determine the Shape of G(b)}

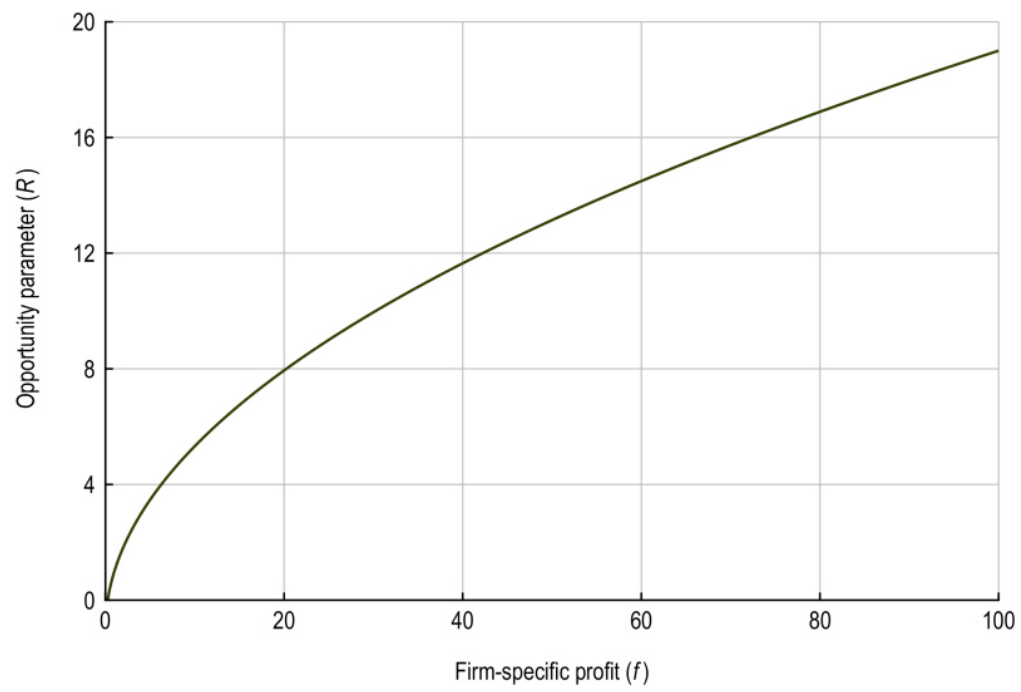

The figure shows the combinations of parameters for which the technology-gap function $G(b)$ is decreasing or inverse $V$ - or $U$-shaped for the maximum industry-specific profit $\bar{b}=100$.

\section{Conclusion}

This paper introduces a model of innovation in which firms choose R\&D expenditures in order to maximize their expected profits subject to the R\&D-expenditure constraint. Using specific combinations of parameter values, I have shown that the model is able to explain the empirical findings of Aghion et al. (2005) and Hashmi (2005). Besides that, I have also shown that the model provides the required predictions for a wider range of parameters around the specific combinations of parameters. I have found that if firms earn similar profits, predictions of the model resemble the empirical finding of Hashmi (2005) for a wider range of parameters. On the other hand, the higher the difference between profits of firms in the industry, the wider is the range of parameters for which the predictions of the model correspond to the empirical findings of Aghion et al. (2005).

The model presented in this paper could be used for deriving alternative testable predictions. For instance, it would be interesting to test whether there is an inverted-U relationship between profitability and innovation of individual firms, or whether the shape of the relationship between profitability and technology gap depends on average differences in profitability in the industry. Should the model receive sufficient empirical sup- 
port, the explanation presented here might have policy implications in several fields, such as competition policy, or formulation of the optimal intellectual property rights regime.

\section{References}

AGHION, P., BLOOM, N., BLUNDELL, R., GRIFFITH, R., HOWITT, P. (2005): Competition and Innovation: An Inverted-U Relationship. The Quarterly Journal of Economics, 120 (2), pp. 701-728

ARTÉS, J. (2009): Long-run Versus Short-run Decisions: RD and Market Structure in Spanish Firms. Research Policy, 38(1), pp. 120-132

ASKENAZY, P., CAHN, C., IRAC, D. (2008): Competition, R\&D and the Cost of Innovation. $\quad$ Retrieved $\quad$ February 20, 2013, from http://halshs.archives-ouvertes.fr/docs/00/58/66/90/PDF/wp200832.pdf

BÉRUBÉ, C., DUHAMEL, M., ERSHOV, D. (2012): Market Incentives for Business Innovation: Results from Canada. Journal of Industry, Competition and Trade, 12(1), pp. 47-65

BOONE, J. (2000): Competition [online]. Center for Economic Research Discussion

Paper No. 2000--104, Retrieved June 7, 2010, from http://papers.ssrn.com/sol3/papers.cfm?abstract_id=249144

BOONE, J. (2008): A New Way to Measure Competition. The Economic Journal, 118(531), pp. 1245-1261

BRUSH, T. H., BROMILEY, P., HENDRIKX, M. (1999): The Relative Influence of Industry and Corporation on Business Segment Performance: An Alternative Estimate. Strategic Management Journal, Vol. 20(6), pp. 519-547

CAVES, R. E., PORTER, M. E. (1977): From Entry Barriers to Mobility Barriers: Conjectural Decisions and Contrived Deterrence to New Competition. The Quarterly Journal of Economics, 91(2), pp. 241-262

GORODNICHENKO, Y., SVEJNAR, J., TERREL, K. (2010): Globalization and Innovation in Emerging Markets. American Economic Journal: Macroeconomics, 2(2), pp. 194-226

HASHMI, A. R. (2005): Competition and Innovation: The Inverted-U Relationship Revisited. $\quad$ Retrieved February 10, 2010, from http://homes.chass.utoronto.ca/ ahashmi/pdf_files/20050812p1.pdf

HASHMI, A. R. (2013): Competition and Innovation: The Inverted-U Relationship Revisited. The Review of Economics and Statistics, 95 (5), pp. 1653-1668

HAWAWINI, G., SUBRAMANIAN, V., VERDIN, P. (2003): Is Performance Driven by Industry- or Firm-Specific Factors? A New Look at the Evidence. Strategic Management Journal, 24(1), pp. 1-16 
KILPONEN, J. K., SANTAVIRTA, T. (2005): When Do R\&D Subsidies Boost Innovation? - Revisiting the Inverted U-Shape. Retrieved February 20, 2013, from http://www.gredeg.cnrs.fr/productivity/workshop/papers/3KilponenSantavirta.pdf

KRAFT, K. (1989): Market Structure, Firm Characteristics and Innovative Activity. Journal of Industrial Economics, 37(3), pp. 329-336

KRČÁL, O. (2010). Competition, Innovation and Technology Gap. In Mathematical Methods in Economics 2010, České Budějovice: University of South Bohemia (ISBN 978-80-7394-218-2, pp. 359-364)

MAURI, A. J., MICHAELS, M. P. (1998): Firm and Industry Effects within Strategic Management: An Empirical Examination. Strategic Management Journal, 19(3), pp. 211-219

MCGAHAN, A. M., PORTER, M. E. (1997): How Much Does Industry Matter, Really? Strategic Management Journal, 18, pp. 15-30

MCGAHAN, A. M., PORTER, M. E. (2002): What Do We Know About Variance in Accounting Profitability? Management Science, 48(7), pp. 834-851

NELSON, R. R, WINTER, G. W. (2002): Evolutionary Theorizing in Economics. The Journal of Economic Perspectives, 16 (2), pp. 23-46

NICKELL, S. J. (1996): Competition and Corporate Performance. The Journal of Political Economy, 104(4), pp. 724-746

OKADA, Y. (2005): Competition and Productivity in Japanese Manufacturing Industries. Journal of the Japanese and International Economies, 19(4), pp. 586-616

POLDER, M., VELDHUIZEN, E. (2012): Innovation and Competition in the Netherlands: Testing the Inverted-U for Industries and Firms. Journal of Industry, Competition and Trade, 12(1), pp. 67-91

PRASAD, A. (2009): Competition and Innovation - A Reexamination of Inverted-U Relationship. $\quad$ Retrieved Janary 13, 2013, from http://www.fma.org/Texas/Papers/RD_Competition_InvertedU.pdf

REY, P., TIROLE, J. (1986): The Logic of Vertical Restraints. The American Economic Review, 76(5), pp. 921-939

RUMELT, R. P. (1991): How Much Does Industry Matter? Strategic Management Journal, 12(3), pp. 167-185

SCHUMPETER, J. A. (1994): Capitalism, Socialism and Democracy. London and New York: Routledge, 437 pages, ISBN 0415107628

TINGVALL, P. G., POLDAHL, A. (2006): Is There Really an Inverted U-Shaped Relation between Competition and R\&D? Economics of Innovation and New Technology, 15(2), pp. 101-118

WERNERFELT, B. (1984): A Resource-based View of the Firm. Strategic Management Journal, 5(2), pp. 171-180. 